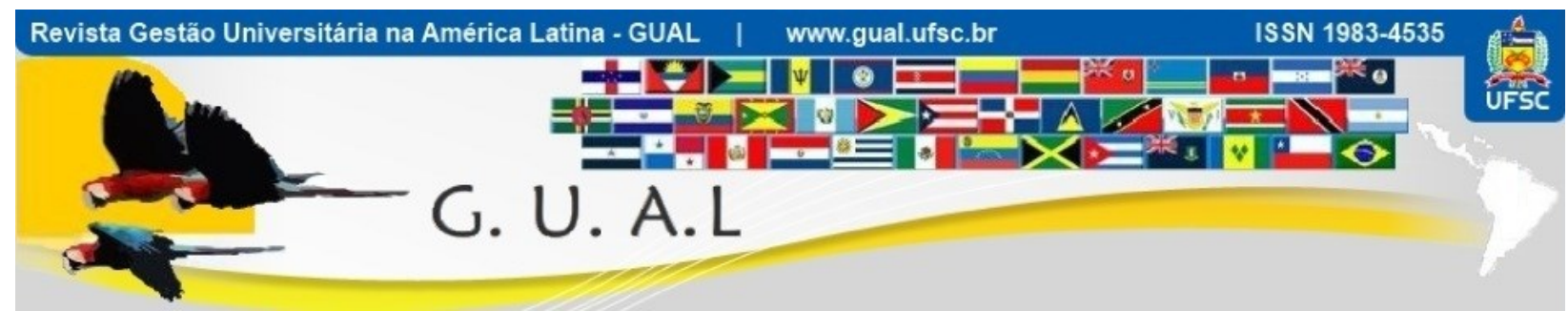

DOI: http://dx.doi.org/10.5007/1983-4535.2017v10n4p157

\title{
METODOLOGIA PARA IDENTIFICAÇÃO DE FATORES ESTRATÉGICOS PARA ACOMPANHAMENTO SISTEMÁTICO DA EVASÃO EM CURSOS DE GRADUAÇÃO
}

\section{STRATEGIC FACTORS FOR SYSTEMATIC MONITORING OF EVASION IN UNDERGRADUATE COURSES}

Ivan Londero Hoffmann, Mestre Universidade Federal de Santa Maria - UFSM ilhoffmann@ufsm.br

Raul Ceretta Nunes, Doutor Universidade Federal de Santa Maria - UFSM ceretta@inf.ufsm.br

Felipe Martins Muller, Doutor Universidade Federal de Santa Maria - UFSM felipe@,inf.ufsm.br

Debora de La Vega Hoffmann, Mestranda Universidade Federal de Santa Maria - UFSM deborahoffmann.ep@gmail.com

Recebido em 25/novembro/2016

Aprovado em 16/outubro/2017

Sistema de Avaliação: Double Blind Review 


\title{
RESUMO
}

A evasão no ensino superior é um fenômeno complexo e representa uma preocupação na gestão das instituições de ensino superior (IES). No Brasil, inexiste orientação oficial para sistematização da coleta e cálculo da evasão. Este trabalho apresenta uma metodologia que permite a identificação de fatores estratégicos capazes de sustentar um acompanhamento sistemático da evasão. $\mathrm{O}$ trabalho foi dividido em duas etapas. Na primeira etapa foi realizada uma sistematização dos dados do ambiente do estudo de caso, para a análise da evasão, utilizando como fonte de dados o Censo. O resultado foi que a partir do modelo de dados do Censo, os indicadores podem ser extraídos de forma sistemática envolvendo todos os cursos e centros de ensino da IES. Na segunda etapa da pesquisa, buscou-se o conhecimento tácito de especialistas da instituição formado por docentes que passaram na função de coordenação de cursos. Esta etapa utilizou o método Delphi de pesquisa científica, para definir de forma consensual, quais fatores são mais importantes nas causas da evasão. Como resultado elaborou-se um painel no qual são elencadas, de acordo com os especialistas, as principais causas de evasão. A partir deste painel, é possível elaborar estratégias e ações que permitam minimizar estes fatores e sua influência nos índices de evasão da instituição.

Palavras-chave: Evasão. Gestão do Conhecimento. Censo da Educação Superior. Delphi.

\begin{abstract}
The dropout rates in higher education is a complex phenomenon and represents a concern in management of higher education institutions. In Brazil, there is no official guidance for systematizing the collection and calculation of evasion. This paper presents a methodology that allows the identification of strategic factors that are capable of supporting a systematic monitoring of dropout rates. The work was divided into two stages. In the first stage was carried out a systematization of data from the case study's environment, for the analysis of dropout rates, using as a data source the Census.The result was that from the Census data model, the indicators can be extracted systematically involving all courses and teaching centers of the higher education institution. In the second stage, the tacit knowledge of the institution's experts that developed by teachers who passed the courses coordination function was sought. This step used Delphi method of scientific research, to define consensually, which factors are more important in causes of evasion. As a result, it was prepared a panel on which the main causes of dropout rates. From this panel, it is possible to elaborate strategies and actions that allow to minimize these factors and their influence in the rates of evasion of the institution.
\end{abstract}

Keywords: Dropout Rate. Knowledge Management. Census of Higher Education. Delphi. 


\section{INTRODUÇÃO}

A evasão de alunos nos cursos de graduação tem sido um dos problemas relevantes para melhoria da gestão acadêmica e financeira das Instituições de Ensino Superior (IES). A desistência do aluno por um curso superior significa prejuízo para si próprio, ao não se diplomar; para o professor, que não atinge sua meta como educador; para a universidade, por não cumprir sua missão institucional de formar o seu alunado; para a sociedade, pelas perdas sociais e econômicas; e para a família, pelo sonho não realizado (SILVA FILHO et al., 2007).

Os gestores já perceberam que para a sobrevivência de suas organizações o conhecimento é de fundamental importância. As organizações que valorizam a gestão de conhecimento como atividade capaz de contribuir significativamente para o alcance das metas organizacionais, precisa identificar quem detém o conhecimento e onde está o conhecimento. Essa importância perpassa os níveis operacionais, tácitos e estratégicos, já que a gestão do conhecimento é considerada um recurso na operação rotineira, no planejamento e direcionamento estratégico e nas realizações das ações gerenciais, favorecendo em todos os níveis a inovação e garantindo vantagens competitivas sustentáveis à organização (JÁCOME, PINHEIRO e DIAS, 2011).

Nas IES o conhecimento que pode ser utilizado para controlar a evasão está disperso no conhecimento individual das pessoas. Na grande maioria das vezes, pessoas com grande vivência universitária e que assumiram funções relacionadas à coordenação de cursos, possuem um conhecimento empírico do tema e desenvolvem ações normalmente intuitivas, na sua área de atuação e em sua capacidade de influência, evitando casos específicos e isolados de evasões de seus alunos. Estas pessoas, com sua formação, conhecimento e habilidade podem ser reconhecidas como especialistas que acumularam nesta experiência um grande conhecimento individual no tema (conhecimento tácito). Este conhecimento precisa ser socializado e compartilhado por todos os profissionais que atuam na instituição, o que favorece a criação de estratégias institucionais consistentes e eficazes.

A percepção da necessidade de gerar conhecimento de maneira sistemática, para uma melhor gestão sobre o fenômeno da evasão nos cursos de Graduação, foi o principal motivador deste trabalho, que encontrou no método Delphi (SILVA FILHO et al., 2009) a metodologia de trabalho e no Censo da Educação Superior a fonte de dados estatísticos necessários. O Censo é um sistema de coleta de dados anual sobre a educação superior que tem como objetivo oferecer à comunidade acadêmica e à sociedade em geral informações 
detalhadas sobre a situação e as grandes tendências do setor. A coleta nos dados do Censo proporciona informações para acompanhamento e definição de políticas educacionais para combater a evasão.

A técnica denominada "Delphi" permite consulta a um grupo de especialistas ou indivíduos especialmente instruídos a respeito de eventos futuros. Por meio de questionários, que pode ser revisto e repassado continuadas vezes até que seja obtida uma convergência das respostas, um consenso, o resultado da técnica representa a consolidação do julgamento intuitivo do grupo. Dois elementos são inerentes a esta técnica: anonimato e retroalimentação. É importante salientar, que sua aplicação depende basicamente da seleção dos participantes e elaboração dos questionários (WRIGHT e GIOVINAZZO, 2000).

Assumindo a Universidade Federal de Santa Maria (UFSM) como "case" da pesquisa, foram levantadas informações sobre a evasão nos cursos de graduação da UFSM, as quais foram levadas a consideração de um grupo de especialistas, composto por professores e coordenadores de curso, com conhecimento sobre o tema da evasão. Desta forma, buscou-se desenvolver uma metodologia que, baseada no conhecimento de especialistas, permita revelar os fatores que mais influenciam e determinam os casos de evasão. A partir do conhecimento destes fatores, recuperados de especialistas, é possível definir ações e estratégias institucionais que tenham por objetivo combater os altos índices de evasão e, consequentemente, melhorar os indicadores de gestão.

\section{REFERENCIAL TEÓRICO}

Esta seção traz as interpretações e os conceitos que fundamentaram a elaboração e execução desta pesquisa. São abordados os seguintes temas: Evasão no Ensino Superior, Gestão do Conhecimento, Censo da Educação Superior e a Técnica Delphi.

\subsection{EVASÃO NO ENSINO SUPERIOR}

A evasão é um dos grandes problemas que cercam o contexto da educação superior, por se tratar de um fenômeno complexo, heterogêneo e macrossocial (BAGGI e LOPES, 2010). Desse modo, define-se evasão no ensino superior como o movimento de o aluno deixar a IES e nunca receber o diploma (TINTO, 1975), ou mesmo, é a interrupção no ciclo dos estudos, em qualquer nível de ensino (GAIOSO, 2005; MOROSINI et al., 2011). Diante deste 
contexto, compreender o fenômeno da evasão, para poder planejar e criar estratégias para minimizar as perdas aos envolvidos, é chave para a gestão universitária.

As pesquisas desenvolvidas em diferentes realidades demonstram que independente do setor pelo qual seja analisada - público ou privado, a evasão impede o retorno, de uma parcela significativa, dos recursos investidos no processo educacional. O consenso que tem prevalecido é de que para o setor público ela é um problema porque faz com que os recursos investidos não tenham o devido impacto social ao qual estão vinculados. Já para o setor privado, a evasão provoca a perda de receita. Porém, para os dois sistemas, a evasão provoca ociosidade de professores, funcionários, equipamentos e espaço físico caracterizando perdas para o conjunto da sociedade (SILVA FILHO et al., 2007).

No ensino superior, a evasão se dá em três níveis (MEC/SESu, 1997) (Lobo, 2012): evasão de curso, quando o estudante desliga-se do curso de origem sem concluí-lo (abandono, transferência interna, aprovação no vestibular para outro curso na mesma instituição); evasão de instituição, quando ele abandona a IES na qual está matriculado (abandono, transferência externa, aprovação no vestibular para curso em outra instituição); e evasão de sistema quando o aluno se ausenta de forma permanente ou temporária da academia (abandono). Um ponto comum entre os três níveis de evasão é a saída do estudante do curso, ou seja, o destino do evadido (outro curso, outra IFES ou fora do sistema) é que define o tipo de evasão. Portanto, a evasão pode ser medida a partir da saída do curso.

A saída do curso é influenciada por três classes de fatores que a influenciam (MEC, 1996): fatores individuais dos alunos, fatores internos as instituições e fatores externos as instituições. Os fatores individuais dos alunos referentes à evasão estão relacionados às habilidades de estudo, personalidade, formação escolar anterior, escolha precoce da profissão, dificuldades pessoais de adaptação à vida universitária, desencanto com o curso escolhido, dificuldades decorrentes de reprovações ou baixa frequência e desinformação a respeito da natureza dos cursos. Já os fatores internos as instituições referentes à evasão, podem se caracterizar por questões peculiares à própria academia, a falta de clareza sobre o projeto pedagógico do curso, baixo nível didático-pedagógico, cultura institucional de desvalorização da docência e estrutura insuficiente de apoio ao ensino. Por fim, os fatores externos às instituições incluem questões como o mercado de trabalho, reconhecimento social na carreira escolhida, conjuntura econômica, desvalorização da profissão, dificuldade de atualizar-se 
perante as evoluções tecnológicas, econômicas e sociais da contemporaneidade e políticas governamentais.

\subsection{GESTÃO DO CONHECIMENTO}

A gestão do conhecimento é um campo de investigação emergente e valorizado nos tempos atuais (ZEIDE \& LIEBOWITZ, 2012). Lee e Yang (2000, p.784) definem gestão do conhecimento como "uma coleção de processos que governam a criação e disseminação do conhecimento com o intuito de alcançar os objetivos organizacionais". A gestão do conhecimento cria um ambiente social e tecnológico favorável para atividades relacionadas com o conhecimento que promovem a criação, armazenamento e compartilhamento de conhecimento (REAICH, GEMINO \& SAUER, 2012).

A criação do conhecimento organizacional precisa ser entendida como um processo que amplia para a esfera da organização o conhecimento criado pelos indivíduos, tornando-o disponível (explícito) compondo a rede de conhecimentos da organização. Para o conhecimento possa ser partilhado deve existir uma cultura de compartilhamento do conhecimento na organização que incentive o indivíduo a participar deste processo de trocas (NONAKA e TAKEUCHI, 1997). Porém, esta Cultura é apenas um dos três pilares necessários para a gestão do conhecimento (COSTA e GOUVINHAS, 2004). A Tecnologia de Informação (TI) e o Mapeamento dos Processos são os outros dois pilares que sustentam o processo da Gestão do Conhecimento (GC).

Nesse contexto, a gestão do conhecimento organizacional relacionado a causas e medidas de combate à evasão em instituições de ensino superior tem sido um desafio. Há muitas informações coletadas, analisadas, compreendidas, mas que permanecem restritas a pessoas, normalmente em coordenações de cursos e pesquisadores, ou em publicações sem abrangência. É estratégico poder contar com dados padronizados e com detalhamento suficiente para compreender as causas e comparar com outros estudos. Os sistemas de informação das instituições de ensino precisam registrar novos dados do estilo de vida e do desempenho acadêmico que suportem novas perspectivas de análise e consigam capturar este conhecimento organizacional setorizado para o uso e aplicação na questão da evasão.

\subsection{CENSO DA EDUCAÇÃO SUPERIOR}

O Censo é um sistema de coleta anual de dados, coordenado e executado pelo Ministério da Educação (MEC) que envolve todas as Instituições de Ensino Superior do 
Brasil, independente da modalidade, ou seja, inclui cursos presencias e a distância, instituições públicas e privadas. Ele reúne informações sobre as instituições de ensino superior, seus cursos de graduação, vagas oferecidas, inscrições, matrículas, ingressantes e concluintes, dados de financiamento estudantil, recursos de tecnologia assistidas disponíveis às pessoas com deficiência, além de outras informações sobre os docentes e suas atribuições dentro da instituição. A exemplo da Plataforma Integrada de Gestão das Instituições Federais de Ensino Superior (PINGIFES), versão anterior do sistema de coleta de informações, que possibilita desenvolver competências necessárias para construir conhecimento organizacional sobre evasão (NUNES, MARCUZZO e HOFFMANN, 2013), o Censo constitui-se de importante fonte para análise de evasão.

Os dados censitários são utilizados de forma articulada com outras informações de políticas públicas da área educacional do governo, como o Exame Nacional de Desempenho de Estudantes (ENADE), Exame Nacional do Ensino Médio (ENEM), Fundo de Financiamento Estudantil (FIES), Programa Universidade para Todos (PROUNI), Reestruturação e Expansão das Universidades Federais (REUNI), Sistema de Seleção Unificada (SISU), além da construção de indicadores como o Conceito Preliminar de Curso (CPC) e Índice Geral de Cursos (IGC). Após a divulgação dos dados consolidados do Censo da Educação Superior, as informações prestadas pela IES passam a figurar como estatística oficial da Educação Superior (BRASIL/MEC, 2014). Esta base pode ser assim explorada para servir de insumo para um modelo de gestão de conhecimento que permita a análise sistêmica da evasão nos cursos de graduação, independente do tipo de instituição e categoria de curso.

\subsection{DELPHI - UMA FERRAMENTA DE APOIO AO PLANEJAMENTO PROSPECTIVO}

A técnica denominada "Delphi" permite consulta a um grupo de especialistas, ou indivíduos especialmente instruídos a respeito de eventos futuros, por meio de uma série de questionários, que são repassados continuadas vezes até que seja obtida uma convergência das respostas, um consenso. Tal consenso representa, na técnica, a consolidação do julgamento intuitivo do grupo. Dois elementos são inerentes a esta técnica: Anonimato e Retroalimentação e sua aplicação depende basicamente da seleção dos participantes e elaboração dos questionários (OLIVEIRA et al., 2008).

De acordo com Giovizazzo (2001) a técnica Delphi está embasada no uso estruturado do conhecimento, da experiência e da criatividade de um painel de respondentes (também 
denominados especialistas, peritos, participantes, respondentes ou painelistas), partindo do pressuposto de que o julgamento coletivo, quando organizado, é melhor que a opinião de um só indivíduo, ou de grupos desprovidos de conhecimentos específicos; assim, a evolução em direção ao consenso representa consolidação do julgamento intuitivo de um grupo de peritos.

A operacionalização da técnica Delphi é realizada por sucessivas rodadas de questionários, aplicados a um grupo de especialistas na área em estudo. Na primeira rodada de opiniões o questionário é enviado ao painel de especialistas e, a partir de seu retorno, as respostas são contabilizadas e analisadas. As questões que obtiverem o consenso estipulado pelo pesquisador são extraídas e o questionário, revisado pelo pesquisador, é novamente enviado aos participantes com a informação dos resultados atingidos na primeira rodada de opiniões. Assim, dá-se início à segunda rodada de opiniões. Nesse momento, os participantes, em anonimato, são solicitados a realizar um novo julgamento de suas opiniões, frente à previsão estatística de cada resposta do grupo, sendo possível mantê-la ou modificá-la. O processo se repetirá até que se atinja o consenso (DALKEY, 1969). De modo geral, em um estudo Delphi, são utilizadas de duas a três rodadas de opiniões.

As vantagens na utilização da técnica Delphi são (SINHA, SMYTH e WILLIAMSON, 2011): a eliminação da influência direta entre pessoas, a possibilidade de acesso a pessoas geograficamente distantes, a produção de grande quantidade de ideias de alta qualidade e especificidade, a possibilidade da reflexão individual e coletiva sobre determinado assunto, a integração e sinergia de ideias entre os especialistas, o fato de agregar conhecimento especializado ao processo, além de ser técnica de baixo custo de operacionalização.

Para este trabalho, a aplicação da técnica Delphi teve como objetivo auxiliar na construção de painéis (forma de apresentação dos resultados dos trabalhos realizados em torno de um tema) a elencar quais os principais motivos da evasão de alunos em uma instituição de ensino superior, servindo de apoio aos coordenadores de curso no acompanhamento sistemático da evasão, contribuindo para a melhoria das práticas de gestão acadêmica.

\section{MÉTOdo DE PESQUiSA E METODOLOGIA PARA IDENTIFICAÇÃo DE FATORES ESTRATÉGICOS SOBRE EVASÃO NO ENSINO SUPERIOR}

Esta seção apresenta os procedimentos metodológicos que nortearam a presente pesquisa (seções 3.1, 3.2 e 3.3), bem como a metodologia para identificação de fatores estratégicos sobre evasão no ensino superior (seção 3.4). 


\subsection{VISÃO GERAL DO MÉTODO}

A pesquisa foi desenvolvida em duas etapas. A primeira foi composta de um levantamento de dados com o objetivo de analisar, quantitativamente o estado atual do índice de evasão na IES alvo, bem como incrementar o conhecimento a respeito das situações que podem levar a evasão. Nesta fase foram estudadas e sistematizadas as formulações para cálculo da evasão, com vistas à definição de um painel composto de indicadores relacionados à evasão na instituição. Na segunda etapa da pesquisa foi proposto um painel de resultados, que considera o trabalho conjunto entre especialistas e os profissionais que trabalham na instituição, e aplicado à técnica Delphi para recuperação do conhecimento tácito sobre evasão. A utilização da técnica Delphi foi o mecanismo utilizado para sistematizar a recuperação do conhecimento, pois permite conhecer a opinião dos especialistas e a obtenção do consenso sobre a importância e priorização de diversos fatores identificados pertinentes ao processo de gestão da evasão, conforme a Figura 1.

Figura 1 Desenvolvimento da pesquisa

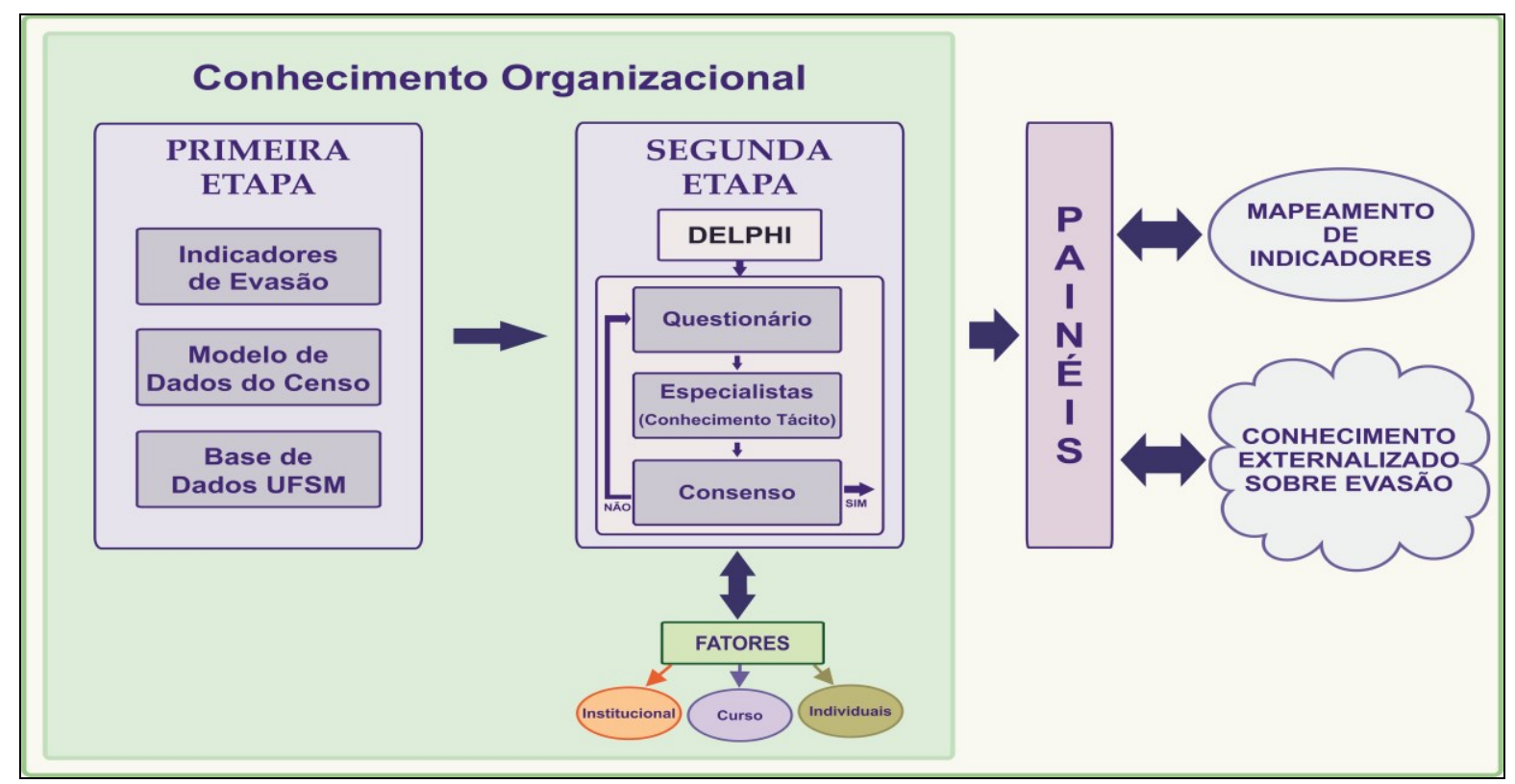

Fonte: Elaborado pelo autor

Como resultado da pesquisa serão gerados painéis que contém o mapeamento dos indicadores e o conhecimento externalizado pelos especialistas sobre a influência dos fatores analisados na evasão na instituição.

A externalização do conhecimento dos especialistas, a partir do método de pesquisa utilizado, permite a ordenação, por importância de cada fator analisado dentro das questões 
apresentadas. Este processo é o resultado da percepção destes especialistas e permite a utilização destes fatores para definir ações e estratégias que podem ser desenvolvidas pela instituição de forma a diminuir os atuais índices de evasão registrados na primeira etapa da pesquisa.

Cabe também destacar que os fatores apresentados e discutidos no presente estudo não esgotam as contribuições feitas até então na literatura, cabendo uma continuidade na pesquisa, que permita ampliar e fortalecer a confiabilidade das investigações sobre o tema.

\subsection{TIPO DE PESQUISA}

A estratégia metodológica adotada foi aprofundar a investigação a respeito de evasão no ensino superior através de um estudo de caso. Segundo Yin (2010) todo o estudo de caso investiga um fenômeno contemporâneo em profundidade e em seu contexto de vida real, especialmente quando os limites entre o fenômeno e o contexto não são claramente evidentes.

A opção pelo estudo de caso permitiu uma análise ampla e detalhada sobre a evasão em uma instituição de ensino superior, tendo como vantagem possibilitar um aprendizado capaz de mudar o comportamento dos profissionais que atuam nas instituições, desenvolvendo com eles as competências necessárias para a consolidação de uma cultura organizacional apropriada para reter o aluno no curso, bem como experimentar a externalização do conhecimento tácito dos especialistas.

Esta pesquisa especificamente classifica-se como de natureza exploratória, pois busca desenvolver, esclarecer e modificar conceitos e ideias, para a formulação de abordagens condizentes para o desenvolvimento de estudos posteriores (Yin, 2010). Uma pesquisa exploratória proporciona maior familiaridade com o problema (explicitá-lo). Pode envolver levantamento bibliográfico, entrevistas com pessoas que tiveram, ou têm experiência práticas com o problema pesquisado. Geralmente, assume a forma de pesquisa bibliográfica e estudo de caso (GIL, 2008).

Quanto à abordagem caracteriza-se por uma pesquisa predominantemente quantitativa, visto que o estudo de caso visa medir de uma maneira precisa os índices de evasão em uma IES considerando forma de ingresso, idade, sexo, área de conhecimento. No entender de Hair et al. (2005), os dados quantitativos devem ser coletados por meio de várias escalas numéricas. As abordagens quantitativas são muito utilizadas quando possui problema de pesquisa ou modelos teóricos bem definidos, como é o caso da evasão. 


\subsection{O ESTUDO DE CASO}

O estudo de caso da pesquisa foi a Universidade Federal de Santa Maria (UFSM). Inicialmente foi identificado como a evasão ocorre nas diferentes formas de ingresso, pelo perfil dos alunos, semestres cursados pelos alunos evadidos, por área de conhecimento e quais cursos possuem as menores e maiores taxas de evasão da instituição, com vistas a entender e analisar o fenômeno da evasão no ambiente de estudo.

A partir da modelo de dados utilizado pelo Censo da educação superior foram gerados relatórios e gráficos para subsidiar os especialistas, com conhecimento no tema a se posicionar sobre a importância de cada um dos aspectos a serem considerados na definição da metodologia de gestão da evasão.

A população estudada no estudo de caso foi constituída por acadêmicos ingressantes, concluintes e matriculados em cursos de Graduação na modalidade presencial existentes nas bases de dados da UFSM, entre os anos de 2009 a 2014. Neste levantamento foram considerados todos os cursos em atividade na instituição, exceto os cursos de criação recente, ou seja, aqueles que começaram a funcionar num período inferior ao prazo máximo de integralização, ou seja, não possuem alunos concluintes, não caracterizando gerações completas.

\subsection{METODOLOGIA PARA IDENTIFICAÇÃO DE FATORES ESTRATÉGICOS SOBRE EVASÃO}

Nesta pesquisa foram selecionados especialistas ativos e que estão ou foram vinculados a coordenação de curso de graduação presencial e que tem/tiveram no mínimo mais de uma gestão no cargo. No total foram consultados 42 especialistas, sendo selecionados 19 coordenadores, todos com o título de doutor. Esses especialistas encontravam-se vinculados a todos os centros de ensino dentro do Campus sede da UFSM.

O questionário com 5 questões que foi estabelecido na parte preparatória foi aplicado aos 19 participantes com uma introdução esclarecendo os objetivos do estudo. Esse questionário foi organizado de forma a permitir que cada participante pudesse emitir um parecer sobre cada um dos fatores que influenciam a evasão e também acrescentar novas sugestões de acordo com sua experiência. Para as 5 questões listadas foi solicitado a cada participante que atribuísse um valor de acordo com sua concordância ao enunciado. A pontuação estabelecida foi de 1 a 5 (Mais importante - Menos importante). 
Ao final de cada questão foi incluído um campo para registro das considerações dos especialistas sobre os temas propostos.

No estudo de caso, para atender aos principais fatores de influência já mencionados na literatura, o questionário foi segmentado em três fatores que influenciam a evasão no ensino superior: fatores referentes às características individuais do estudante, como aspectos pessoais, motivacionais e causas relacionadas ao desempenho acadêmico; fatores internos às instituições; e fatores relacionados ao curso.

Após ser aplicado, o questionário final é revisado para que possíveis divergências de termos possam ser corrigidas. Concluídas as devidas alterações no instrumento de coleta de dados, o questionário do estudo de caso foi submetido a um pré-teste, encaminhado para dez pessoas que trabalham e têm experiência na área acadêmica, a fim de colher sugestões e melhorias no modelo para adaptar à realidade na instituição pesquisada. De acordo com Marconi e Lakatos (2003), o teste-piloto tem como uma das principais funções, testar o instrumento de coleta de dados.

Considerando que a proposta metodológica é a obtenção do consenso, nesta pesquisa adotou-se o percentual de $70 \%$ para definir o consenso nas respostas, ou seja, apenas são considerados como obtenção de consenso quando $70 \%$ das respostas individuais tiverem aderência ao gabarito (resposta classificada como "certa" - alinhada ao consenso).

Para os itens que não se obtém o consenso na primeira rodada de aplicação do questionário, é necessário uma reformulação do questionário levando em consideração as sugestões dos especialistas e posteriormente realizada nova rodada de aplicação do questionário. Este processo pode ser repetido até que a divergência de opiniões entre especialistas tenha se reduzido a um nível satisfatório. A resposta da última rodada é considerada como consenso do grupo de especialistas.

Após a aplicação do questionário os dados foram importados para análise no software estatístico SPSS versão 18. Para análise das questões relativas às causas mais importantes que contribuem para que os estudantes abandonem seus cursos de graduação, foi utilizada a técnica estatística de distribuição de frequências, onde os resultados são apresentados em forma de gráficos e tabelas de frequência. Segundo Malhotra (2006) a distribuição de frequência analisa uma variável de cada vez, e tem como objetivo demonstrar quantas vezes determinada resposta foi dado a uma variável e quanto cada grupo de respostas de cada variável representa (percentual) em relação ao total de respostas. 


\section{RESULTADOS ALCANÇADOS NA PRIMEIRA ETAPA DA PESQUISA}

Nessa seção, são apresentados os principais resultados da pesquisa sobre o estudo de caso (primeira etapa). Considerando a evolução de matrículas, ingressantes e concluintes no período analisado, a Tabela 1 apresenta a evolução da taxa de evasão geral da instituição.

Para a análise dos dados, em função da utilização da fórmula do estudo de Silva Filho et al. (2007), houve a necessidade de incluir também os alunos evadidos e concluintes no período de 2008 .

Tabela 1 Evolução de Matriculas, Ingressantes e Concluintes

\begin{tabular}{l|r|r|r|c}
\hline Ano & Ingressantes & Concluintes & Matrículas & Taxa de Evasão (\%) \\
\hline 2009 & 2372 & 1422 & 10856 & 7,87 \\
\hline 2010 & 2654 & 1586 & 11797 & 10,77 \\
\hline 2011 & 3313 & 1797 & 13843 & 9,94 \\
\hline 2012 & 3658 & 1739 & 15313 & 10,48 \\
\hline 2013 & 3851 & 1999 & 16490 & 13,46 \\
\hline 2014 & 3596 & 574 & 16328 & 11,68 \\
\hline
\end{tabular}

Fonte: SIE - Sistemas de Informação UFSM (2015).

$\mathrm{Na}$ Tabela 1, pode-se observar que houve uma queda significativa de ingressantes e concluintes no ano de 2014, em decorrência de que, quando foi feita a coleta dos dados não entraram os alunos ingressantes e concluintes do segundo semestre de 2014. Porém em 2012 e 2013, o aumento do número de ingressantes deve-se à implantação de novos currículos, ocasionando a transferência interna de alunos de um curso para outro.

A evolução histórica da taxa de evasão anual da UFSM comparada com a das IES Públicas do Brasil é apresentada na Figura 2.

Figura 2 Comparativo das Taxas de Evasão na UFSM e nas IES Públicas

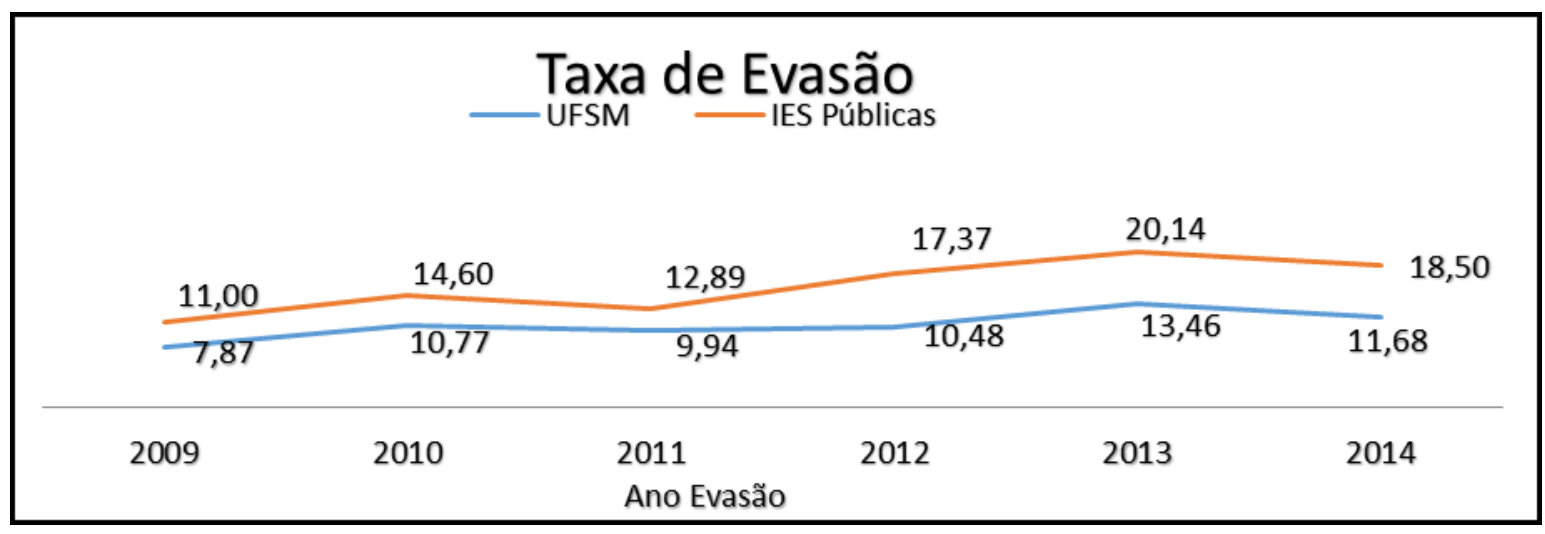

Fonte: SIE - Sistemas de Informação UFSM (2015). 
Como se pode observar na Figura 3, a taxa de evasão da UFSM manteve-se inferior, no período de 2009 a 2012, em relação à taxa nas IES Públicas, apresentando taxa maior no período de 2013. Porém, nota-se que estes dados pouco explicam a evasão no contexto de uma IES.

Nas seções seguintes, exploram-se os dados disponíveis no Censo para aprofundar a análise.

\subsection{PERFIL DA AMOSTRA}

Nessa etapa, é detalhado o perfil dos participantes da amostra com relação ao gênero. Para os ingressantes por Vestibular e Processo Seriado, 54,2\% são mulheres (11758) e 45,8\% são homens (9919), conforme detalha a Tabela 2. Nas Demais Formas de Ingresso, o sexo feminino corresponde a $59,7 \%$ da amostra enquanto o sexo masculino a 40,3\%. Na Tabela 2 , a soma dos concluintes e evadidos não coincide com o total de ingressantes, pois na fórmula do cálculo da taxa de evasão anual, fez-se necessário incluir os alunos que concluíram no período entre 2008 a 2014 e com ingresso anterior a este período.

Tabela 2 Gênero Alunos

\begin{tabular}{|c|c|c|c|c|c|}
\hline \multirow{2}{*}{ Forma de Ingresso } & \multirow{2}{*}{ Total } & \multicolumn{2}{|c|}{ Feminino } & \multicolumn{2}{|c|}{ Masculino } \\
\hline & & Frequência & $\%$ & Frequência & $\%$ \\
\hline \multicolumn{6}{|c|}{ VESTIBULAR PROCESSO SERIADO } \\
\hline Ingressantes & 21.677 & 11.758 & 54,2 & 9.919 & 45,8 \\
\hline Concluintes & 9.162 & 5.061 & 55,2 & 4.101 & 44,8 \\
\hline Evadidos & 8.074 & 3.775 & 46,8 & 4.299 & 53,2 \\
\hline $\begin{array}{ll}\text { DEMAIS } & \text { FORMAS } \\
\text { INGRESSO } & \end{array}$ & & & & & \\
\hline Ingressantes & 6.004 & 3.585 & 59,7 & 2.419 & 40,3 \\
\hline Concluintes & 2.098 & 1.276 & 60,8 & 822 & 39,2 \\
\hline Evadidos & 1.745 & 969 & 55,5 & 776 & 44,5 \\
\hline
\end{tabular}

Fonte: SIE - Sistemas de Informação UFSM (2015).

Considerando os ingressantes pela forma de ingresso Vestibular/Processo Seriado, observa-se, na Tabela 2 que a evasão é maior entre os alunos do sexo masculino enquanto que, no Processo Seriado as mulheres são a maioria. Do total dos evadidos, 53,2\% são do sexo masculino e $46,8 \%$ do sexo feminino. Analisando os ingressantes pelas Demais Formas de Ingresso, observa-se que a evasão é um pouco mais elevada entre os alunos do sexo feminino $(55,5 \%$ contra $44,5 \%$ para o sexo masculino). 
Considerando a idade dos alunos no momento do ingresso, constatou-se que a idade média dos alunos ingressantes na instituição, nas formas de ingresso Vestibular e Processo Seriado, foi 20,2 anos e que a idade dos alunos concluintes na conclusão do curso foi 24,2 anos, enquanto que dos alunos evadidos foi 21,3 anos. Já nas Demais Formas de ingresso, a idade média geral dos acadêmicos ingressantes foi 26,8 anos, dos concluintes 29,1 anos e dos evadidos, 28.2 anos.

\subsection{TAXA DE EVASÃO ANUAL}

Após verificar uma distorção na taxa de evasão em alguns cursos, ao longo da série histórica, os dados referenciados a partir do desenrolar desta pesquisa serão do ano em que os cursos tiveram alunos concluintes. A Figura 3 agrega as taxas de evasão das formas de ingresso Vestibular e Processo Seriado e Demais Formas de Ingresso.

Figura 3 Taxa de Evasão por Ano de Evasão

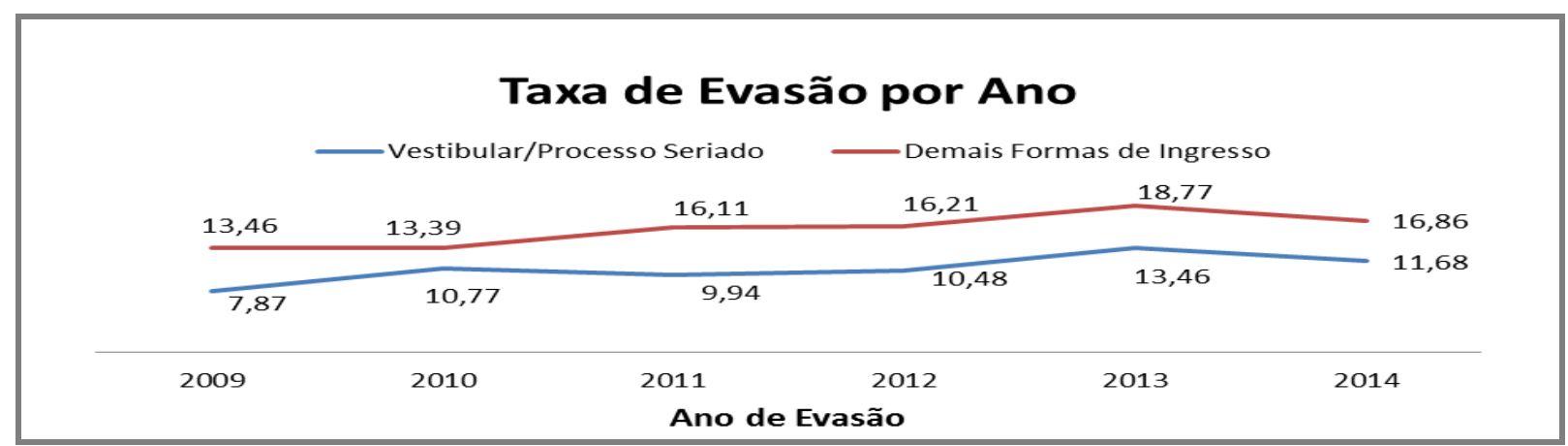

Fonte: SIE - Sistemas de Informação UFSM (2015).

Analisando a Figura 3, a taxa de evasão na forma de ingresso Vestibular/Processo Seriado esteve sempre menor que os alunos que ingressaram pelas Demais Formas de Ingresso. As maiores taxas de evasão ocorreram nos alunos que ingressaram nas Demais Formas de Ingresso, sendo no ano de 2013 a maior taxa $(18,77)$ e no ano de 2010 a menor taxa $(13,39)$.

$\mathrm{Na}$ Figura 4, é possível observar os resultados da taxa de evasão por área de conhecimento no período compreendido entre 2009 a 2014, com os seguintes agrupamentos relacionados às formas de ingresso: i) Vestibular e Processo Seriado e ii) Demais formas de ingresso. 
Figura 4 Taxa de Evasão por Área de Conhecimento

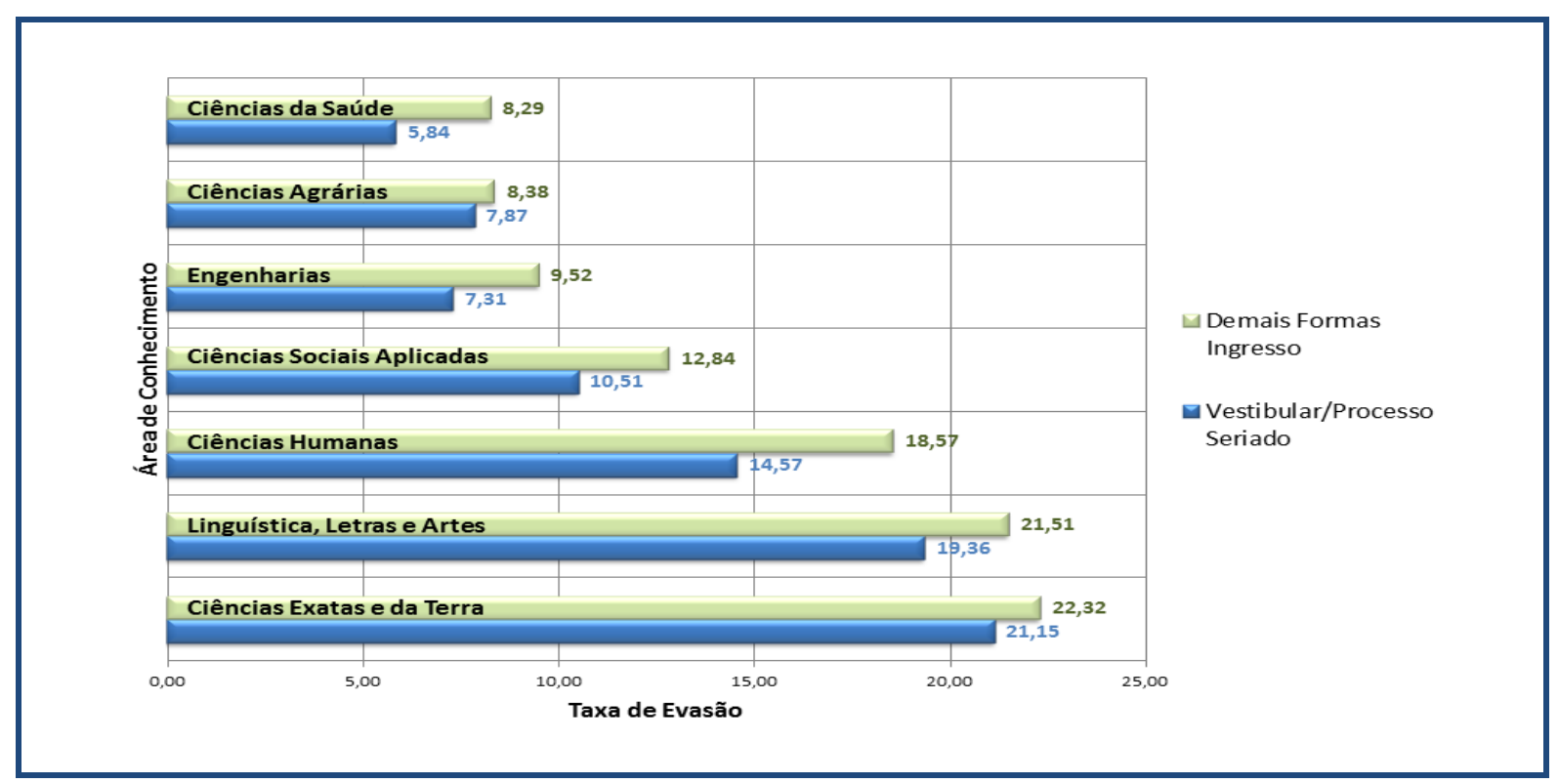

Fonte: SIE - Sistemas de Informação UFSM (2015).

As maiores taxas de evasão foram na área de conhecimento das Ciências Exatas e da Terra, em todas as formas de ingresso, e as menores nas áreas de Ciências da Saúde, Ciências Agrárias e Engenharias.

Foram analisados 99 cursos nas sete áreas de conhecimento. A seguir, a Tabela 3 destaca em cada área de Conhecimento o curso que aponta, respectivamente, as menores e as maiores taxas de evasão no período de 2009 a 2014.

Tabela 3 Cursos com menor e maior taxa de evasão por Área de Conhecimento

\begin{tabular}{l|l|r}
\hline \multicolumn{1}{c|}{ Área de Conhecimento } & \multicolumn{1}{c}{ Cursos } & $\begin{array}{c}\text { Taxa } \\
\text { Evasão }\end{array}$ \\
\hline \multirow{2}{*}{ Ciências Exatas e da Terra } & Química Industrial & 9,26 \\
\cline { 2 - 3 } Ciências Agrárias & Matemática - Licenciatura e Bacharelado & 41,19 \\
\hline \multirow{2}{*}{ Ciências da Saúde } & Medicina Veterinária & 3,14 \\
\cline { 2 - 3 } & Curso Superior de Tecnologia em Agronegócio & 25,90 \\
\hline \multirow{2}{*}{ Ciências Humanas } & Medicina & 1,36 \\
\cline { 2 - 3 } & Educação Física - Bacharelado & 13,39 \\
\hline \multirow{2}{*}{ Ciências Sociais Aplicadas } & Psicologia & 5,60 \\
\cline { 2 - 3 } & Bacharelado em Filosofia - Noturno & 37,81 \\
\hline \multirow{2}{*}{ Engenharias } & Direito Diurno & 1,94 \\
\cline { 2 - 3 } & Ciências Sociais - Bacharelado & 21,77 \\
\hline \multirow{2}{*}{ Linguística, Letras e Artes } & Engenharia Civil & 5,20 \\
\cline { 2 - 3 } & Curso Superior de Tecnologia em Fabricação & 23,98 \\
\hline & Mecânica & 6,50 \\
\hline & Artes Cênicas - Interpretação Teatral & 52,84 \\
\hline
\end{tabular}

Fonte: SIE - Sistemas de Informação UFSM (2015). 
Da Tabela 3, pode-se observar que a área de conhecimento de Linguística, Letras e Artes possui, no curso de Bacharelado em Letras-Português/Literaturas, a maior taxa de evasão, enquanto a área de conhecimento Ciências da Saúde possui, no curso de Medicina a menor taxa. Apesar de todas as análises serem realizadas pelas áreas de conhecimento, podese observar que, dentro de uma mesma área de conhecimento encontram-se diferenças significativas em relação à taxa de evasão. Por exemplo, o curso de Medicina Veterinária tem uma das menores taxas de evasão e o Curso Superior de Tecnologia em Agronegócio apresenta uma taxa significativamente elevada. Todas as áreas de conhecimento tiveram uma grande variação entre a menor e a maior taxa de evasão. Este comportamento pode ser parcialmente explicado pelas variáveis socioculturais e econômicas.

\section{RESULTADOS ALCANÇADOS NA SEGUNDA ETAPA DA PESQUISA}

Esta seção apresenta os resultados da fase de externalização de conhecimento realizada através da aplicação da técnica Delphi (segunda etapa). Juntando os painéis de cada questão é possível apresentar um Painel Geral (vide Quadro 1) representando o conhecimento tácito externado. Este painel pode ser utilizado para a definição de políticas institucionais, envolvendo estratégias e ações, que possam influenciar positivamente na permanência dos acadêmicos no curso/instituição e terem sucesso na conclusão dos seus cursos de graduação.

Quadro 1 Painel dos especialistas.

\begin{tabular}{|c|c|}
\hline $\begin{array}{l}\text { Questão 1 - Causas Acadêmicas } \\
\text { relacionadas ao Curso }\end{array}$ & $\begin{array}{l}\text { 1. Mercado de trabalho para concluintes no curso } \\
\text { 2. A estrutura dos cursos } \\
\text { 3. Infraestrutura necessária } \\
\text { 4. Corpo docente do curso } \\
\text { 5. Atendimento da coordenação }\end{array}$ \\
\hline $\begin{array}{l}\text { Questão } 2 \text { - Causas Acadêmicas } \\
\text { relacionadas à Instituição }\end{array}$ & $\begin{array}{l}\text { 1. O reconhecimento da Instituição na comunidade } \\
\text { 2. Assistência Estudantil } \\
\text { 3. Ambiente de estudo e vivência } \\
\text { 4. Serviços oferecidos } \\
\text { 5. Deslocamento até o campus }\end{array}$ \\
\hline $\begin{array}{l}\text { Questão } 3 \text { - Aspectos pessoais e } \\
\text { motivacionais dos acadêmicos }\end{array}$ & $\begin{array}{l}\text { 1. Falha em relação à opção de curso } \\
\text { 2. Frustração de expectativas prévias em relação ao } \\
\text { curso } \\
\text { 3. Visão de futuro e qualidade de vida do egresso na } \\
\text { profissão } \\
\text { 4. Dificuldades financeiras } \\
\text { 5. Integração acadêmica }\end{array}$ \\
\hline $\begin{array}{l}\text { Questão } 4 \text { - Causas relacionadas ao } \\
\text { desempenho acadêmico }\end{array}$ & $\begin{array}{l}\text { 1. Baixa frequência e reprovações } \\
\text { 2. Formação prévia } \\
\text { 3. Facilidade de aprendizado }\end{array}$ \\
\hline
\end{tabular}




\begin{tabular}{|c|c|}
\hline & $\begin{array}{l}\text { 4. Tempo disponível para o curso } \\
\text { 5. Distração em outras atividades }\end{array}$ \\
\hline $\begin{array}{l}\text { Questão } 5 \text { - Ordem de importância } \\
\text { dos fatores avaliados pelos } \\
\text { especialistas }\end{array}$ & $\begin{array}{l}\text { 1. Aspectos pessoais e motivacionais dos acadêmicos } \\
\text { 2. Causas relacionadas ao desempenho acadêmico } \\
\text { 3. Causas Acadêmicas relacionadas ao Curso } \\
\text { 4. Causas Acadêmicas relacionadas à Instituição }\end{array}$ \\
\hline
\end{tabular}

Fonte: Elaborado pelo autor.

O Painel Geral, ou Painel dos Especialistas, ordena, para cada questão apresentada, as variáveis mais importantes a serem consideradas no combate à evasão.

A partir deste quadro a instituição poderá direcionar ações e estratégias, dentro do seu planejamento, expressado no Plano de Desenvolvimento Institucional (PDI) em que tipo de ações terá os maiores e melhores resultados. As questões estão ordenadas pelo tipo de causa que pode ser atacados e dentro desta causa, quais os variáveis mais importantes que pelo conhecimento reportado pelos especialistas permite melhores resultados nas ações desenvolvidas.

Conforme apresentado no Quadro 1 do painel dos especialistas, a questão de maior relevância para a evasão são os "Aspectos pessoais e motivacionais dos acadêmicos" (resultante da questão 5 do questionário) e dentro desta questão a variável que mais induz o acadêmico a evadir é a "falha em relação à opção do curso". Neste aspecto, ações como, por exemplo, a promoção de eventos para apresentação dos cursos aos candidatos, é de grande importância. Do mesmo modo, o desenvolvimento de ações junto às escolas de ensino médio para que a opção dos alunos seja mais consciente e com conhecimento da profissão na qual pretende atuar, podem obter impacto satisfatório.

\section{CONSIDERAÇÕES FINAIS}

A evasão é um fenômeno altamente nocivo ao sistema de educação superior, pois representa o insucesso na formação, um investimento não completado e uma frustração para os alunos. Estudos detalhados sobre seu comportamento e investigação sobre uma nova metodologia para identificar fatores estratégicos que causam evasão foram, assim, alvo deste trabalho.

Visando proporcionar fatores e indicadores para acompanhamento e definição de políticas educacionais para reconhecimento e combate da evasão, este trabalho calculou a evasão na IES do estudo de caso, com base nas informações armazenadas nos bancos de dados da instituição e das informações coletadas pelo MEC no Censo do Ensino Superior. 
Para esta análise foram elaborados gráficos sobre os indicadores envolvendo diferentes cursos e centros de ensino da instituição.

A partir da análise inicial realizada, que permite conhecer o estado atual da evasão na IES, buscaram-se, na instituição, especialistas com profundo conhecimento sobre o tema. $\mathrm{O}$ critério de seleção pode variar, mas neste trabalho foi elencado como representativos docentes que labutaram na função acadêmica de coordenadores de curso, com larga experiência acadêmica e administrativa em sua vivência na instituição. Estes especialistas foram convidados a se manifestarem a partir de um questionário com questões elaboradas a partir da literatura onde diferentes fatores foram inseridos para que estes fossem priorizados pelos especialistas. Através da aplicação do método Delphi o consenso entre os especialistas foi obtido, resultando num Painel com prioridades para cada questão elaborada.

O Painel elaborado explicita aos gestores institucionais o conhecimento tácito de especialistas em evasão e habilita estes a conhecerem diferentes priorizações de fatores com graus de influência nos aspectos de causa de evasão. De posse destas informações é possível elaborar estratégias e ações que permitam atacar diferentes problemas que ocasionam altos índices de evasão nos cursos da instituição.

Salienta-se que a metodologia proposta permitiu sistematizar a obtenção do conhecimento sobre os principais fatores que influenciam a evasão de alunos nos cursos superiores em uma IES pública, bem como definir estratégias de ações voltadas à redução dos índices de evasão.

O trabalho permitiu demonstrar também que através da base de dados do Censo da Educação Superior é possível analisar e caracterizar o perfil dos alunos evadidos na evasão no ensino superior. Esta sistemática é de extrema importância para permitir que diferentes IES, mesmo adotando diferentes sistemas de informação e modelagem interna de dados, possam realizar comparações a respeito das suas taxas de evasão.

A identificação de fatores que compõem as principais causas da evasão, a partir de uma sistemática bem definida que explora a agregação e externalização do conhecimento tácito, demonstra o potencial de técnicas como a Delphi no contexto da gestão da evasão. Porém, salienta-se a sensibilidade do método para com o questionário, que neste trabalho foi objeto de uma vasta revisão literária sobre o tema da evasão.

A priorização dos fatores que influenciam a evasão foi atingida na segunda fase desta pesquisa, no qual, utilizando o conhecimento dos especialistas foram priorizados para cada 
uma das questões analisadas, quais fatores são mais determinantes na evasão. Isto permitiu propor painéis estratégicos que facilitam a gestão e permitem a elaborações de ações para redução dos índices de evasão.

Finalmente, foi observado que o grupo de especialistas, através da metodologia proposta, podem também auxiliar na sistematização da identificação de indicadores que permitam criar painéis dinâmicos de acompanhamento da evasão.

\section{REFERÊNCIAS}

BAGGI, C. A. S.; LOPES, D. A. Evasão e Avaliação Institucional no Ensino Superior: uma Discussão Bibliográfica. Avaliação. Campinas; Sorocaba, SP. v. 16, n.2, p. 355-374, jul. 2010. Disponível em: <http://goo.gl/OYhcQn>. Acesso em: 13 dez. 2013.

BRASIL. MINISTERIO DA EDUCAÇÃO. INSTITUTO NACIONAL DE ESTUDOS E PESQUISAS EDUCACIONAIS - INEP - Censo da Educação Superior 2014, Resumo Técnico - Brasília, DF. 2014.

COSTA, P. E. C.; GOUVINHAS, R. P. Gestão do conhecimento: quebrando o paradigma cultural para motivar o compartilhamento do conhecimento dentro das organizações. ENCONTRO NACIONAL DE ENGENHARIA DE PRODUÇÃO, v. 24, 2004.

DALKEY, N. C. The Delphi method: an experimental study of group opinion. Santa Monica (CA): Rand Corporation 1969.

GAIOSO, N. P. de L. O Fenômeno da evasão escolar na educação superior no Brasil. Brasília: 2005.

GIL, A. C. Como elaborar projetos de pesquisa. 4. ed. São Paulo: Atlas, 2008.

GIOVIZAZZO, R. A. Modelo de aplicação da metodologia Delphi pela internet vantagens e ressalvas. Administração online [periódico na internet]. 2001 [citado 2011 jan 10]; 2(2): [cerca de 10p]. Disponível em: http://www.fecap.br/adm_online/art22/renata.htm.

HAIR, J. JR.; JOSEPH, F.; BABIN, B.; MONEY, A. H. \& SAMOUEL, P. Fundamentos de Métodos de Pesquisa em Administração. Porto Alegre: Bookman, 2005.

JÁCOME, P. M. J.; PINHEIRO, P. R. L.; DIAS G. A. Aceitação do Outsourcing Enquanto Estratégia de Gestão do Conhecimento. In: XXXV Encontro Nacional de Pós Graduação em Administração - EnANPAD , Anais...04-07 de setembro, Rio de Janeiro, 2011.

LEE, C. C. \& YANG, J. (2000). Knowledge value chain. Journal of Management Development, 19(9), 783-793. 
LOBO, M. B. de C. M. Panorama da evasão no ensino superior brasileiro: aspectos gerais das causas e soluções. ABMES Cadernos. Brasilia, set./dez. 2012.

MALHOTRA, N. Pesquisa de marketing - Uma orientação aplicada, 4 ${ }^{\mathrm{a}}$ Ed. Porto Alegres: Bookman, 2006.

MARCONI, M. A.; LAKATOS, E. M. Fundamentos de Metodologia Científica. São Paulo: Atlas, 2003.

MEC. Diplomação, retenção e evasão nos cursos de graduação em instituições de ensino superior públicas. Avaliação: Revista de rede de avaliação institucional da educação superior. Campinas, v. 1, n. 2, p. 55-65, dez. 1996.

MEC/SESU. Comissão Especial de Estudos sobre a Evasão nas Universidades Públicas Brasileiras. Brasília: ANDIFES/ABRUEM/SESU/MEC. 1997.

MOROSINI, M. C.; CASARTELLI, A. O.; SILVA, A. C. B.; SANTOS, B. S.; SCHMITT, R. E.; GESSINGER, R. M. A Evasão na Educação Superior no Brasil: uma análise da produção de conhecimento nos periódicos Qualis entre 2000-2011. Porto Alegre/RS Brasil. Faculdade de Educação - FACED. Pontifícia Universidade Católica do Rio Grande do Sul- PUCRS. 10 f. p.1-10, 2011.

NONAKA, I.; TAKEUCHI, H. Criação do conhecimento na empresa: como as empresas japonesas geram a dinâmica da inovação. Rio de Janeiro: Campus, 1997.

NUNES, R. C.; MARCUZZO, M. M. V.; HOFFMANN, I. L. Conhecimento organizacional sobre evasão a partir do modelo de dados do PINGIFES. XIII Colóquio Internacional sobre Gestão Universitária nas Américas. Anais... 27-29 de Novembro, Buenos Aires Argentina, 2013.

OLIVEIRA, J.D.O.; COSTA, M.M.; WILLE, M.F. \& MARCHIORI, P.Z. Introdução ao Método Dephi. 2008.

REAICH, B. H., GEMINO, A. \& SAUER, C. (2012). Knowledge management and projectbased knowledge in it projects: A model and preliminary empirical results. International Journal of Project Management, 30(6), 663-674

SINHA, I. P.; SMYTH, R. L. \& WILLIAMSON P. R. Using the Delphi technique to determine wich outcomes to measure in clinical trials: recommendations for the future based on a systematic review of existing studies. Plos Med. 2011; 8(1):1-5.

SILVA FILHO; LOBO; ROBERTO, L. H.; OSCAR, L.; MARIA, B. C. M.; MOTEJUNAS, P. R. Cadernos de Pesquisa, Fundação Carlos Chagas. set/dez. - 2007-- v.37, nº 132.

Disponível em: <http://goo.gl/k4ciUF>. Acesso em:04 dez. 2013.

SILVA FILHO; JOSÉ P. As Reprovações em Disciplinas Nos Cursos de Graduação da Universidade Federal do Ceará (UFC) no Período de 2000 a 2008 e suas Implicações na Evasão Discente. 2009. 70 f. Dissertação (Mestrado em Educação) - Programa de Pós- 
Graduação em Políticas Públicas e Gestão da Educação Superior. Universidade Federal do Ceará. 2009.

TINTO, V. Dropout from higher education: a theoretical synthesis of recent research.Review of Educational Research, 45: 89-125. 1975.

WRIGHT, J. T. C.; GIOVINAZZO, R. A. Delphi uma ferramenta de apoio ao planejamento prospectivo. Cad Pesq Admin. 2000; 1(12):54-65.

ZEIDE, E. \& LIEBOWITZ, J. (2012). Knowledge management in law: A look at cultural resistance.Legal Information Management, 12(1), 34-38.

YIN, R. Estudo de caso. In: Planejamento e Métodos. Tradução: Ana Thorell. 4a ed. Porto Alegre: Bookman, 2010. 